\title{
ESTUDANTES, PESQUISADORES, ESCRITORES NO CRUZAMENTO DE LÍNGUAS E CULTURAS
}

\author{
Karine Rouquet-Brutin
}

\begin{abstract}
RESUMO: Esta comunicação deseja abrir alguns caminhos de reflexão sobre as questões subjetivas, epistemológicas e políticas implicadas no atravessamento de fronteiras. Serão abordados os percursos de estudantes que vão à França para realizar pesquisas acadêmicas e seus procedimentos no confronto com outra cultura, outra língua, outro regime de discurso. Serão, ainda, objeto desta comunicação escritores, pensadores e pesquisadores, que, vindos de outros lugares, escolheram ficar na França e escrever em francês: Julia Kristeva (acadêmica, psicanalista, escritora de origem búlgara), François Cheng (poeta, tradutor, acadêmico de origem chinesa), Janine Altounian (tradutora de Freud, ensaísta, armênia nascida na França). É no deslocamento, no atravessamento de fronteiras, que emerge a questão da necessidade da língua e da cultura do outro para formular-se.
\end{abstract}

PALAVRAS-CHAVE: Interculturalidade. Língua. Poder.

RÉSUMÉ: Cette communication souhaite ouvrir quelques pistes de réflexions sur les enjeux subjectifs, épistémologiques, politiques impliqués par le franchissement des frontières. Je m'intéresserai aux démarches des étudiants venus poursuivre leur recherche en France confrontés à une autre culture, une autre langue, un autre régime de discours et à celles d'écrivains, penseurs, chercheurs, venus d'ailleurs qui ont choisi de rester en France et d'écrire en français : Julia Kristeva (universitaire, psychanalyste, écrivain d'origine bulgare), François Cheng (chercheur, traducteur, poète d'origine chinoise), Janine Altounian (traductrice de Freud, essayiste, d'origine arménienne). C'est à l'occasion du déplacement et du franchissement des frontières qu'émerge la question qui a besoin de la langue et de la culture de l'autre pour se formuler.

MOTS-CLÉS: l'interculturalité. Langue. Puissance.

\section{INTRODUÇÃO}

"Atravessar outro pensamento, outra cultura, qualquer que seja ela, é um convite a retornar, a requestionar o que não se questiona", é o que declara François Julien, filósofo e sino-especialista (especialista em civilização chinesa), em sua conferência de abertura de um colóquio que nós organizamos na Cidade Universitária de Paris, em 2003, intitulado "Estudar, pesquisar além: estudantes estrangeiros na universidade 
francesa" ${ }^{1}$. Em minha apresentação, eu retomarei a fala de François Julien. Como sua viagem à China, civilização que se desenvolveu quase totalmente separada do mundo ocidental, e sem referência ao mesmo, lhe permitiu "de qualquer maneira retomar o senso do pensamento europeu", "pensar o impensado da filosofia ocidental".

É sob o angulo das questões epistemológicas, mas também subjetivas e políticas, implicadas pelos deslocamentos dos estudantes, que eu gostaria de abrir esta reflexão sobre as construções identificadas no cruzamento de línguas e de culturas. Há em torno de dois milhões e quinhentos mil estudantes viajando pelo mundo em busca de estudos. Em 2009, 267000 entre eles vieram estudar na França. Mais de um terço dos estudantes inscritos no doutorado, na França, são de nacionalidades estrangeiras ${ }^{2}$. Esta situação influencia as medidas de acolhimento dos Países. Se os Estados Unidos ou o Canadá procuram atrair a atenção dos estudantes na totalidade de sua formação, a França privilegia o acolhimento em nível de mestrado e de doutorado, em seus acordos de parceria acadêmica ${ }^{3}$.

As consequências deste caso são: uma grande parte dos estudantes chega à França sem o beneficio de uma formação inicial em uma universidade francesa: eles entram em um ambiente social e escolar estrangeiro e precisam se contextualizar, normalmente em pouco tempo, com a instituição universitária, com certo regime de discurso e com os conhecimentos considerados adquiridos, em termos de normas e de códigos intelectuais e metodológicos. Isso não se limita ao aspecto universitário, visto que os problemas encontrados pelos estudantes são bem mais amplos.

Estudar, pensar e escrever em outra língua engaja aquele que se arrisca em uma aventura singular. Tal aventura pode ser dolorosa, conduzir a uma situação de impasse. Mas ela também pode se tornar o fermento de uma nova liberdade.

O trabalho com os estudantes me sensibilizou para as dinâmicas particulares, resultantes da passagem de fronteiras, do deslocamento de objetos de pesquisa de uma língua a outra, da relação com sua própria língua e com sua própria história, história que

\footnotetext{
1 François Jullien, "Conférence d'ouverture ", in Etudier, chercher ailleurs : les étudiants étrangers dans l'université française, Paris, Cité-débats, Octobre 2004, p. 29-49.

2 Selon I'UNESCO et Ronan Vourc'h, "Les doctorants: profils et conditions d'études". Rapport de l'Observatoire de la Vie Etudiante, ${ }^{\circ} 24$, juin 2010.

3.Selon M. Jean-Yves de Longeau, sous-directeur de l'égalité des chances et de la vie étudiante à la Direction Générale pour l'Enseignement Supérieur et l'Insertion Professionnelle/DGESIP lors d'un débat à la Cité internationale, "L'odyssée d'une utopie » en mai 2010.
} 
se torna mais aguda pela experiência de vida e pelo trabalho universitário em um solo estrangeiro. Ou seja, para o aluno que permite o deslocamento, a travessia de fronteiras, e a transposição dos objetos de pesquisa e da língua de trabalho científico, minha hipótese é que a afiliação a outro país, outro idioma, outro sistema universitário, permite criar uma separação diferenciadora. Esta separação possibilita formular, a partir de outro espaço e de outro contexto, uma questão intimamente vinculada ao país de origem.

Esclarecemos assim o espaço, o contexto e a experiência que permitem formular esta hipótese e as demais que se seguem, na posição de professora agregada à Universidade Paris 7 - minha disciplina é a literatura; eu acolho, ao lado de meus colegas psicanalistas, os estudantes estrangeiros na filial do Escritório (Bureau) de Ajuda Psicológica Universitária (BAPU) - Pascal $^{4}$. Este escritório é um centro de orientação psicanalítica para os estudantes que necessitam de um apoio psicológico. Ele é um dos estabelecimentos da Fundação Saúde dos Estudantes da Franca ${ }^{5}$. A filial do BAPU foi aberta, em 2000, no centro de uma estrutura, o "Relais Social International", ela mesma inscrita em um local de convívio e de moradia, a Cidade Internacional Universitária de Paris, que associa mais de cinco mil estudantes, vindos de todos os países do mundo. A Cidade Internacional é o local histórico de uma utopia nascida após a Primeira Guerra Mundial: favorecer o acordo entre os povos através das trocas estudantis ${ }^{6}$.

No meu ponto de vista, que é o de uma professora que trabalha em relações estreitas com psicanalistas, em uma estrutura independente da universidade, mas, ainda assim, ligada à mesma estrutura inscrita em um local altamente simbólico, contextualizando todas as implicações políticas do dever de acolhimento, eu não pude deixar de perceber toda a opressão do mundo ecoando em todos os temas da pesquisa, em todas as disciplinas.

\footnotetext{
${ }^{4}$ Les étudiants sont accueillis par des psychanalystes.

${ }^{5}$ La Fondation Santé des Etudiants de France assure le suivi médical et les études de jeunes gens empêchés d'étudier en raison de leur maladie. Elle dispose de 13 cliniques, certaines sont consacrés à des jeunes gens souffrant de troubles somatiques, d'autres accueillent des jeunes gens souffrant de troubles psychiques. La devise de la FSEF est : " Etudier quand même ».

${ }^{6}$ La création de la Cité internationale universitaire de Paris eut lieu dans le contexte du mouvement pacifiste de l'entre-deux guerres. Ses fondateurs, acteurs publics ou mécènes, porteurs d'un idéal humaniste, souhaitaient créer " une école des relations humaines pour la paix ». Sa vocation est de contribuer à l'entente entre les peuples en favorisant les amitiés entre les étudiants, les chercheurs, les artistes du monde entier.
} 
Eu darei aqui uma amostra destes temas na minha primeira parte, onde interrogo os papéis subjetivos, epistemológicos e políticos que sustentam, a meu ver, o trabalho dos estudantes. Na minha segunda parte, abordarei a experiência de escritores, de intelectuais vindos do exterior, que escolheram, por diversas razões, algumas vezes sob a restrição ou a impossibilidade de fazer de outra maneira, continuarem na França, de se tornarem cidadãos deste país, e de produzirem sua reflexão na língua desta terra de adoção. Eu escolhi Julia Kristeva, François Cheng, Janine Altounian. Julia Kristeva e François Cheng são escritores e pesquisadores: eles vêm de países marcados pelo Totalitarismo - a Bulgária, a China - sem, no entanto, lhes reivindicar como tais. Janine Altounian é armênia; ensaísta e tradutora de Freud, filha de um sobrevivente do genocídio, ela trabalha sobre os efeitos do genocídio e como o tema é transmitido às gerações futuras. Todos são autores de uma criação e de uma reflexão que se constrói entre duas culturas e dois idiomas; eles ilustram a experiência particular de destinos mestiços, forjados na passagem de fronteiras geográficas, geopolíticas e linguísticas. Neste sentido, a referência a esses autores me pareceu importante para esclarecer a dinâmica da mestiçagem, dinâmica sensível, contudo muitas vezes inconsciente na ação daqueles que partem para estudar no estrangeiro, pesquisar adiante, em busca de outro terço, para dar lugar, legitimação, direito de existência a uma reflexão que poderia, talvez, não ter vez no país de origem. E é, pela oportunidade do deslocamento e da travessia de fronteiras, que emerge a questão da necessidade da língua e da cultura alheias para se formular.

\section{ESTUDAR, BUSCAR ADIANTE. PERCURSOS DE ESTUDANTES}

Desde o enunciado dos temas de pesquisa dos estudantes, surgiu esta constatação impressionante: um grande número de temas de mestrado e de doutorado tem relação com o país de origem, e em todas as disciplinas.

1. Os temas de pesquisa que envolvem o país de origem

É muito importante a lista de temas comparativos que permitem avaliar os costumes, as práticas, as legislações cruzando as perspectivas: em Direito (A proteção 
do patrimônio na Venezuela e na Europa: França, Espanha); (A proteção coletiva dos consumadores na França e na Argentina); em Linguística (A temporalidade nas línguas chinesa e francesa); em Ciências da Educação (A inserção do computador na escola: um estudo levado na França e no México). Em Teatro (A influência do kathakali (teatro dançado na Índia) sobre Ariane Mnouchkine e Peter Brook) ${ }^{7}$

Ou ainda os temas que não envolvem uma comparação, mas trazem diretamente o país de origem: em Cinema ("confabulação de alteridade no cinema brasileiro: o caso de Cidade de Deus" ${ }^{\prime 8}$ ), (a filmografia histórica representando na Coréia do Sul a guerra das duas Coréias); em Direito (A reparação dos danos ambientais em direito positivo de Benim); em Sociologia (As associações de desempregados na Argentina), (O lugar da mulher nos programas de luta contra a pobreza no México ${ }^{9}$ ) (As populações deslocadas na Colômbia); em Arquitetura (As marcas da ditadura na cidade de Buenos Aires); em Historia (Os conflitos ambientais na Espanha durante a ditadura), (A criminalidade na Tunísia durante o período colonial); em Economia (O trabalho assalariado das mulheres na África Subsaariana) (As populações deslocadas na Angola). Numerosos são os temas que abordam a condição feminina no Yémen, no Libano, na Argélia, no Marrocos, no México, na Tunísia, nas Filipinas e que questionam o lugar da mulher nas sociedades muçulmanas e conservadoras, a discriminação salarial entre homens e mulheres.

Certos temas revelam o envolvimento imediatamente político do deslocamento. Vem-se à França para abordar e trabalhar uma questão proibida em seu próprio país. Assim, uma estudante turca vem fazer seu mestrado em estudos políticos sobre "A implicação das mídias turcas nos assassinatos políticos dos líderes de oposição". Uma estudante libanesa veio defender sua dissertação de mestrado em Psicologia sobre os Kamikazes (candidatos à morte voluntária) do Hezbollah no contexto do conflito com Israel. Uma estudante chilena, em Ciências Sociais, questiona as formas artísticas como modalidades de elaboração da ditadura.

Menos numerosos são os casos daqueles que vêm à França para trabalhar um autor ou uma questão ligada ao contexto Francês, justificando precisamente sua presença na França para construir uma bibliografia ou consultar as obras de referência.

\footnotetext{
${ }^{7}$ Cette thèse a été soutenue par Harbeen Arora en 2003.

${ }^{8}$ Amaranta Cesar dos Santos: "La fabulation et la figuration de l'altérité dans le cinéma brésilien contemporain : Cidade de deus, du livre au film ». Cette thèse soutenue en décembre 2008 a reçu les félicitations à l'unanimité du jury.

Thèse soutenue en 2009 par Cécile MagaÑa, "La gendérisation des programmes de lutte contre la pauvreté au Mexique ».
} 
Este procedimento é primeiramente característico dos estudantes europeus, mas não somente. Se uma grande parte dos temas abordados na França menciona seu próprio país, um menor número, em oposição, dedica-se ao país de acolhimento, enquanto que se poderia pensar que uma das razões da viagem de estudos seria de abordar o país em função do tema escolhido. No entanto, quase todos os estudantes dizem ter a necessidade de se vincularem ao pensamento teórico francês, desenvolvido pelas equipes de pesquisa às quais eles almejam se agregar, e ao pensamento europeu como ferramenta, não como finalidade de estudo.

No entanto, uma estudante estrangeira que vem produzir e defender na França uma tese sobre Saussure, sobre a Revolução Francesa ou sobre a legislação européia, é guiada pelo fato de trabalhar em outra língua os objetos que relevam outra cultura, a utilizar o olhar desta cultura e de suas instituições como ferramenta de pensamento, a “des- territorializar seu pensamento", como dizia François Julien.

Eu acredito que o deslocamento dos estudantes, na França, relaciona dois movimentos: o primeiro, este de uma afiliação consentida pelo país de acolhimento, à sua cultura, às suas instituições universitárias, ao desenvolvimento de sua reflexão teórica e de suas metodologias de pesquisa. A partir desta afiliação e através da disciplina eleita, há o outro movimento, este de retorno ao país de origem, o país natal, para interrogar, para colocá-lo em perspectiva, desenvolver uma questão que implica a ajuda dos conhecimentos constituídos na França que, adicionados aos saberes teóricos lá adquiridos de onde se vem constituir uma base de análise.

Eu não sei se esta maneira de proceder é própria ao fato de estudar na França ou se ela é um efeito do deslocamento, se ela se produzirá com tal repetição constante em qualquer país de acolhimento. A questão da língua aqui seria determinante para poder responder a questão: numerosos países da Europa propõem seus cursos em inglês em conformidade com os padrões de desenvolvimento cientifico à maneira anglo-saxã. Parece-me que escolher a França e optar pelo idioma de trabalho, o francês, significa querer herdar a história e as tradições filosóficas e científicas deste país.

Seria sempre verdade que passar uma fronteira, estudar no exterior, é suscetível de dar uma posição a partir da qual um tema pode se tornar, face ao país de onde ele vem, com olhar para trás projetando-se em direção ao futuro. 
Tal foi o percurso que retraça François Julien, na abertura do primeiro colóquio "Estudar, pesquisar além: os estudantes estrangeiros na universidade francesa". Mas ele escolheu ir estudar na China, em Pequim e em Xangai. As reflexões que se seguem ilustram magistralmente a estratégia epistemológica do desvio por outro país e outra cultura para poder pensar a própria. "Seria para ele de des-territorializar o pensamento".

\section{DESPATRIAR O PENSAMENTO ${ }^{10}$.}

Hoje, professor na Universidade Paris 7-Diderot, diretor do Instituto de pensamento contemporâneo e autor de vários livros que fundam um diálogo entre o pensamento ocidental e o pensamento chinês, ele retornou aos tempos e as razões que lhe levaram a se reencontrar na posição de estudante em Pequim e em Xangai, em uma China que saía do comunismo. Jovem estudante da Escola Normal Superior, ele desejava requestionar o pensamento grego. Para um helenista, se abria a via do sânscrito, mas ele continuaria nas origens indo-européias, no mundo da gramática, da metafísica. Ora, ele buscava um lugar externo para a língua e para o espírito, e um pensamento tão explícito e tão comentado como o pensamento grego: foi assim que a China se impôs. A China constitui, para ele, uma "heterotopia"11, "um outro lugar" produzindo " uma des-nacionalizaçao da alma".

"Como tomar consciência daquilo que pensamos e do que não pensamos, mas que, mesmo impensado, constitui o próprio pensamento? ${ }^{12 "}$ Tal é a questão filosófica que alimenta a pesquisa de François Jullien e conduz a estratégia epistemológica do desvio por um além para pensar o aqui, que uma demasiada familiaridade de língua e de história tornava inacessível: isto seria, para ele, romper com a história da filosofia, "sair do banho do pensamento indo-europeu", "sair de tudo que o sustenta, que o tenciona, que o justifica por esta forma de extrapolação, abstraindo pelo exterior chinês".

Assim, sua passagem pela China lhe permitiu "poder, em certas medidas recolocar em perspectiva o pensamento europeu": "pensar o impensado da filosofia ocidental". Assim ainda, ele explica, descobrir que o verbo "ser" não existe no chinês clássico lhe permite perceber que a China seria constituída fora do pensamento da

\footnotetext{
${ }^{10}$ François Jullien, « Conférence d'ouverture », op.cit.

${ }^{11}$ François Jullien précise que I'hétérotopie est un concept opposé à celui d'utopie. Il est forgé par Michel Foucault dans la préface de Les mots et les choses.

${ }^{12}$ François Jullien, in Nouvelles clés, n`34, été 2002.
} 
essência, da ontologia e dos grandes filosofemas: o ser, Deus, a liberdade. Ele conclui: "atravessar uma outra forma de pensar, uma outra cultura, qualquer que ela seja, é ser convidado a retornar, a re-questionar o que não se questionaria, as partes implícitas, as escolhas escondidas de nossa razão; e recolocá-las em questão". A exterioridade chinesa permite interrogar a filosofia ocidental naquilo que ela não pensa e que portanto the fundamenta: "eu estudei chinês para ler Platão"13, afirma o filósofo.

Para retornar aos procedimentos dos estudantes, a imersão em outra cultura, o sofrimento de perder as palavras e a gramática, o imenso trabalho de identificação dos códigos e as leis implícitas que regem, não somente a vida cotidiana e a vida universitária, mas o discurso a apreender, a confrontação à exigência de escrever sua tese para este destinatário que é a universidade francesa, em um idioma que impõe outra visão de mundo, cria uma separação diferenciadora, uma terceira instância por onde não cessam de se abrir os pontos de perspectiva sobre o país de onde se vem, sobre o natal. Observadores atentivos dos costumes e das tradições discursivas deste estranho país onde eles escolheram estudar, os jovens são conduzidos pelo trabalho de afiliação a questionar, em recíproca, sua cultura universitária, pois eles são comumente todos os locais, todos os laços, sua identidade colocada que se torna objeto de questionamento.

E é outro efeito da viagem e da travessia de fronteiras: o desvio pelo exterior, pelo distante, permite questionar o próximo, o natal. "O exílio, atravessado do estrangeiro, é reconhecimento do próprio. Ao longe, descobre-se o próximo, e ir em direção ao longe é uma aproximação do natal", nos explica o psicanalista Edmundo Gomez Mango, em um artigo notável "A língua e o exílio": "porque só e longe da origem, aproxima-se para se refugiar, para encontrar asilo em sua intimidade próxima $\ldots, 14$

\section{ESCRITORES E PENSADORES ENTRE DUAS LÍNGUAS E DUAS CULTURAS}

Julia Kristeva, François Cheng, Janine Altounian e Jamel Eddine Bencheikh retraçaram seus percursos em seus escritos, testemunhando sobre o deslocamento de suas inscrições na língua e na cultura do país de acolhida. Essa cultura tornou-se o

\footnotetext{
${ }^{14}$ Edmundo Gomez Mango, «La langue et l'exil », Cahiers intersignes : Parcours d'exil, n³, automne 1991, p. 122 et 123.
} 
caldeirão em que eles forjaram, desde a pátria perdida, mas sempre presente, novas identidades que nos interpelam: "Sou um monstro de cruzamentos", proclama Julia Kristeva, enquanto François Cheng se declara "passador" de um diálogo entre o Oriente e o Ocidente; "passador" como Janine Altounian, mas, para ela, trata-se da passagem que ela mesma abriu para a herança de seus ascendentes armênios no seio da cultura do país onde seus pais se refugiaram, a França.

\section{Julia Kristeva, a híbrida, a migrante}

Julia Kristeva é de origem búlgara: foi criada em um meio francófilo animado pelas luzes do pensamento francês, nessa parte da Europa que sofreu com o totalitarismo soviético. De maneira previsível, prossegue seus estudos na França, onde se casa; é hoje uma acadêmica e psicanalista francesa, escritora, ensaísta e romancista que trabalha em inúmeros campos de reflexão, entre os quais a reflexão sobre o estrangeiro em Estrangeiros a nós mesmos ${ }^{15}$. Recebeu, em 2004, o primeiro prêmio Holberg, criado por decisão do Parlamento norueguês para reverenciar uma pesquisa excepcional em ciências humanas. Ela se apresenta a si mesma assim: escritora, ensaísta, de origem búlgara, francesa de adoção, americana de coração e cosmopolita.

Apoiaremo-nos principalmente no livro Estrangeiros a nós mesmos e no artigo "Escrever em francês"16 para retraçar seu percurso tal como ela o apresenta a nós.

Remarquemos primeiramente que a passagem de uma fronteira lhe abre um campo novo, a psicanálise, e desloca suas pesquisas, voltadas inicialmente para a linguística e a semiologia, em direção às profundezas da psique e os segredos da alma humana. Desde então, aquela sobre quem Barthes escrevia "ela muda o lugar das coisas", desloca-se entre as línguas e as disciplinas das quais ela não cessa de alargar os limites, as fronteiras. É, aliás, essa posição fronteiriça que é dada como ponto de perspectiva: “é situando-se na interface de diversas 'disciplinas' que se pode ter uma chance de elucidar ao menos um pouco o que permanece sempre enigmático: a psicose,

\footnotetext{
${ }^{15}$ Julia Kristeva, Étrangers à nous-mêmes, Folio essais, 1988.

16 Julia Kristeva, , in Tu parles !? Le français dans tous ses états, Paris, Flammarion, 2000, p. 63-74.
} 
a sublimação, a crença e o niilismo, a paixão, a guerra dos sexos, a loucura materna, a ira assassina"

É no terreno da língua que se experimenta mais violentamente o conflito ligado ao abandono da língua natal e a reivindicação última do ser "dedicado a uma palavra estranha, estrangeira, nem daqui nem de lá", de onde emerge a reivindicação de uma identidade "nômade". Também a seguimos no processo sem condescendência, mas não sem humor, que ela instaura contra seu país de adoção.

"Os franceses, aqueles que são porque pensam."

Como especialista da língua, ela detalha as virtudes particulares da língua. Ela sublinha "a clareza lógica, a impecável precisão do vocabulário, a nitidez da gramática da língua francesa" que seduzem seu "espírito de rigor", mas aponta as possíveis derivas do raciocínio quando a argumentação, diz ela, "se esvazia em sedução, em ironia". A observação de nossos traços de caráter nacional se faz mais violenta e mais rude quando ela trata da polidez e da evidência francesas, do gosto francês, que ela define assim: "um ato de polidez entre pessoas que partilham a mesma retórica em uma sociedade estável" e que opõem ao estrangeiro "um tecido social compacto e um orgulho nacional imbatível". E repreende os autóctones desse país que "se identificam à sua fala polida e querida" ao ponto de desconsiderar os que fazem um uso inadequado da língua francesa, os que, por seus hábitos alimentares ou de vestuário, transgridem "o gosto universal, ou seja, francês". Kristeva ironiza, aliás, revirando o cogito de Descartes: "os franceses, aqueles que são porque pensam". E distribui qualidades e defeitos a esse povo que fez a mais radical das revoluções, esses franceses que são "os rabugentos mais alegres do mundo": "Escrever em francês seria então traduzir o sofrimento em alegria de viver"

Essa distância crítica colérica ou cheia de humor com relação à língua e à cultura produzida por "uma sociedade estável" se desdobra no conflito interior, na culpabilidade, no sofrimento ligado ao abandono de sua língua natal, língua do corpo, “das pulsões inomináveis na vizinhança do sentido e da biologia". "Há certo matricídio no abandono de uma língua natal", "Bulgária meu sofrimento", diz ela, destacando que existe "France" em "souffrance" [N.T.: existe "França" em "sofrimento"].

"Há certo matricídio no abandono de uma língua natal."

17 Julia Kristeva, in La haine et le pardon : Pouvoirs et limites de la psychanalyse III, Paris, Fayard, 2005.

${ }^{18}$ Todas as citações são do artigo « Écrire en français », op. cit. 
A língua búlgara é para ela uma "língua quase morta", inicialmente metaforizada em "água longínqua", "fonte original", e depois "velho corpo" cadaverizado, "cripta enterrada", "reservatório estagnante que apodrece e se desagrega" sobre o qual ela construiu uma "nova morada", o francês, e uma "serenidade pontuada de palavras francesas". Entre as duas línguas, em que uma se substituiu à outra, reina a antítese dada como irreconciliável entre "os dourados negros dos ícones ortodoxos" e "a aparência lisa das palavras francesas polidas como a pedra das pias de água-benta". E ela designa esses momentos em que "uma onda que não é de palavras, mas que tem sua música bem própria" lhe impõe "uma sintaxe desajeitada" e "essas metáforas abissais" que lhe vêm de sua língua materna eslava, levando-a a "transgredir o gosto francês". Resulta daí "um ser híbrido", resultado de um "transplante"; "o monstro que surge" (a imagem é muito forte e designa o surgimento antinatural, em um gesto de auto engendramento violento, de um alien) vê-se destinado a uma palavra "estranha, estrangeira, nem daqui, nem de lá", a ser "um monstro de cruzamentos".

\section{Escritora migrante "enraizada em nenhuma língua e nenhum sangue"}

Todas essas imagens e metáforas traduzem um conflito violento, irredutível, destinando-a dolorosamente à posição de estrangeira. Posição que será finalmente reivindicada de forma militante, combativa e profética: o "eu" estranho surgido no texto "Escrever em francês" se dissolve no "nós" dos "escritores migrantes", "enraizados em nenhuma linguagem e nenhum sangue", "diplomatas do dicionário", "negociantes genéticos", "judeus errantes do ser", "humanidade nômade" de onde viria talvez a salvação ou a respostas às crispações identitárias que assolam o planeta. Ao mesmo tempo, "a outra língua da escrita" é designada como o lugar onde se trava o "diálogo"; ela também, como François Cheng, emprega essa palavra, entre as duas línguas.

Desdobram-se aqui representações míticas que proclamam a salvação por meio do deslocamento, do nomadismo, da errância, do estrangeiro e da estranheza contra o sedentarismo dos "cidadãos autênticos, logo militares", nos diz ela, e que convidam à subversão das fronteiras.

2. François Cheng, ou o diálogo entre o Oriente e o Ocidente 
François Cheng é acadêmico, tradutor, poeta, romancista; foi eleito para a Academia francesa em 2002 e relata seu percurso de escritor entre duas línguas muito distantes em $O$ diálogo; Uma paixão pela língua francesa ${ }^{19}$. Foi a revolução maoísta ocorrida no momento em que estudava na França que forçou François Cheng a ficar no país onde tinha vindo prosseguir seus estudos. Ele se instituiu inicialmente em uma identidade de "passador" entre as duas culturas, traduzindo para o chinês os poetas franceses e depois divulgando na França a pintura e a poesia chinesas. Primeira atividade do "passador", a tradução. Mas é somente muitos anos mais tarde, quando pensa em voltar à poesia e escolhe escrever em língua francesa que se ilustra o diálogo entre as duas línguas.

\section{Um casamento de amor e de razão com a língua francesa}

Ele também detalha as virtudes da língua francesa. As palavras "clareza", "rigor", "precisão" aparecem frequentemente em sua obra: "língua de rigor e de precisão" para esse poeta chinês que se declara sempre impulsionado a "mais rigor na formulação, mais fineza na análise”. Essas qualidades da língua desabrocham maravilhosamente nos textos teóricos. Contudo, é ao explicitar o dilema sentido no momento de escolher a "ferramenta" linguística de sua poesia que ele chega a esclarecer a relação entre as duas línguas.

Esse poeta utiliza de forma recorrente os termos de "osmose", de "simbiose", de "casamento", "casamento de amor e de razão", para ilustrar o diálogo íntimo: "eu abracei a língua e esposei toda uma tradição poética". Cheng coloca essa aliança sob o signo do amor, da "presença comum" (retomando o título de uma coletânea de René Char) e da aliança exogâmica; sua poesia, nos diz ele, é tirada de duas tradições poéticas "simbiotizadas" (é ele que constrói esse neologismo). A língua materna é qualificada de "velha ama-de-leite fiel"; se o francês foi adotado como ferramenta de criação, a outra língua não foi por isso apagada, nem mesmo colocada em surdina; ela continua a agir oferecendo imagens a metamorfosear.

\section{O artesão do diálogo entre Oriente e Ocidente}

É no sentido de uma perspectiva crítica que se inaugura sua tentativa de fazer dialogar "duas culturas que cavam entre elas o maior fosso que se possa imaginar". No fim desse itinerário em que explica porque escolheu o francês como língua de criação,

\footnotetext{
${ }^{19}$ François Cheng, Le dialogue ; Une passion pour la langue française, Desclée de Brouwer, 2002. Todas as citações são extraídas dessa obra.
} 
ele tenta estabelecer passarelas, ver como o pensamento oriental e o ocidental podem unir-se, interpenetrar-se e enriquecer-se. Apóia-se sobre a cosmologia chinesa e seus três elementos, o Yin, o Yang e o Vazio Mediano, para avaliar as contribuições das duas civilizações e a maneira pela qual elas podem enriquecer-se mutuamente, ou mesmo completar-se no plano filosófico. Destaca a mais importante contribuição civilizatória do Ocidente que isolou o conceito de sujeito e protegeu seu estatuto por meio de regras de direito. A China, que não desatou suficientemente a pessoa humana dos laços que a envolvem, sofre, segundo "seus intelectuais modernos" de um "déficit do lado do dois" ("o dois designando o Sujeito frente ao Objeto ou o Sujeito frente a um outro Sujeito"); mas está, pelo contrário, do lado do "três", por sua conceitualização do Vazio Mediano que conduz o Ying e o Yang a um processo de interação e de transformação mútua. Assim, se a China tira proveito ao aproximar-se escola do Ocidente no que concerne o "pensamento do dois", o Ocidente, de sua parte, pode inspirar-se na China no que concerne o "pensamento do três".

Vê-se aqui, então, que essas perspectivas críticas de uma cultura por parte de outra atuam tanto com relação à cultura de acolhida (Julia Kristeva), quanto tentam uma síntese filosófica das duas culturas, como o faz François Cheng. Uma de suas figuras é o descentramento com relação à cultura de origem e seu instrumento, o julgamento e a avaliação crítica, emprega sempre afetividade. Mas onde houve uma espécie de corte doloroso, em Kristeva, entre a nova morada construída pontuada de palavras francesas e o pântano de águas estagnantes de sua língua natal, tudo se apresenta sob o signo da harmonia, da continuidade, da filiação feliz na passagem do chinês ao francês, da qual Cheng ilustra as correspondências nos dois ideogramas escolhidos para a página de rosto. Enquanto Kristeva propulsiona-se, após um nascimento violento, no sentido de uma hibridez nômade e guerreira, recusando a filiação do sangue e da linguagem, François Cheng chega, ao fim de um longo trabalho de filiação, a se "re-enraizar" no "fosso" entre as duas civilizações e a tecer aí pontos de passagem.

Mas, nesses dois autores, a outra língua abre as portas para a criação da língua poética ou literária e para uma experiência que ambos designam como "uma experiência do ser". Ela permite a François Cheng "renomear as coisas como novas" e "se reenraizar", "não apenas na terra de acolhida, mas propriamente no ser". E Kristeva evoca "a alquimia da nomeação", em que ela está "sozinha com o francês. Nomear o ser me 
faz ser". Finalmente, essa experiência do ser chega, nesses dois autores, a transcender os conflitos e as posições identitárias.

Do mesmo modo, para François Cheng, a língua de empréstimo foi a ocasião para um distanciamento global, evitando o perigo dos clichês e das referências prontas, permitindo a ele "desprender-se de seu passado" e efetuar a passagem "entre duas línguas de natureza tão diferente que cavam entre elas o maior fosso que se possa imaginar", e nesse fosso "se re-enraizar", "não somente em sua terra de acolhida, mas no ser propriamente". Todos os três falam da experiência do ser ligada ao esforço de nomeação.

A outra língua abre as portas para a criação da língua poética ou literária e essa experiência é a de uma libertação ou de uma nova identidade, que Cheng formula assim: "estar ao mesmo tempo em si e em outro, ou então à frente de si em uma perspectiva multidimensional". Kristeva faz do destino dos escritores híbridos e migrantes uma resposta às crispações identitárias que assolam certas regiões do mundo e o aproxima daquele de uma "identidade nômade que não quer mais ficar quieta na sua cadeira".

3. Janine Altounian: a transmissão de uma herança traumática sob a proteção de uma outra língua

Janine Altounian não teve que escolher sua língua. O francês lhe foi imposto no lugar do armênio falado anteriormente, "uma língua hipotecada por mim em uma espécie de noite psíquica". E é em 1981, sobre o efeito da tomada de reféns no consulado da Turquia em setembro, ato terrorista quebrando pela primeira vez um silêncio de meio século sobre o genocídio armênio, que ela decide publicar o jornal de deportação de seu pai em Les temps modernes e depois empreender esse vasto afresco constituído pela trilogia ${ }^{20}$ Abra-me somente os caminhos da Armênia, A sobrevivência $\mathrm{e}$ $O$ intraduzível, em que elabora os efeitos do genocídio sobre os descendentes dos sobreviventes. Ela mostra como a língua e as instituições do país de acolhida, convocados para o lugar de um terceiro, permitem aos sobreviventes de assassinatos coletivos colocar em circulação um patrimônio aniquilado e efetuar um trabalho de

\footnotetext{
20 Janine Altounian, «Ouvrez-moi seulement les chemins d'Arménie ». Un génocide aux déserts de l'inconscient, Paris, Les Belles Lettres, coll. "Confluents psychanalytiques ", 1990. La survivance/Traduire le trauma collectif, Paris, Dunod, coll. "Inconscient et culture ", 2000. L'intraduisible. Deuil, mémoire et transmission, Paris, Dunod, coll. «Psychismes », 2005.
} 
nomeação, de luto e de transmissão. Daí a necessidade para o escritor-herdeiro de passar pela língua e instituições da cultura de acolhida para "tentar simbolizar o acontecimento não-ocorrido com seus pais" que lhes reteve prisioneiros do terror: "entre o terror do assassinato e a libertação de sua dominação, é preciso que se construa, na maior parte do tempo nas gerações seguintes, o interstício de uma função simbolizante: a capacidade de nomear esse acontecimento e depois de de-portar o desmoronamento traumático da história no campo da representação, no registro das palavras"21.

\section{A salvação pela escola da república}

Janine Altounian proclama sempre sua dívida com a Escola da república, "esse terceiro [...] fiador da vida e da cultura", "terceiro incapaz de compreender, mas capaz de acolher" que foi para ela, como também para outros sobreviventes de assassinatos coletivos, uma "mãe adotiva"; ela estava, de fato, forçada a "uma dupla filiação entre pais extermináveis e outros que, por enquanto, não o seriam”. A instituição escolar trazia para a criança prisioneira do silêncio e da dominação traumática de seus ascendentes "uma língua, um imaginário cultural diferenciadores e, assim, produzia sem querer um terceiro". Aprender a língua do outro, ter prazer com as palavras, com a cultura e com a literatura dele oferecia a ela a possibilidade de fugir "para um mundo fictício onde, ao lado do assassinato familiar demais, haveria os prazeres da vida, prazeres com os outros e com a poesia". Ao mesmo tempo em que se experimentava a capacidade de passar de seu mundo ao dos outros, eram aprendidas palavras para testemunhar. "Passar pelo outro e sua linguagem para formar a sua"; tal foi a operação de mestiçagem salvadora que lhe permitiu mais tarde assegurar a transmissão de sua herança "deportando o patrimônio traumático na língua do outro".

A transmissão diferida da herança sob a proteção da língua do outro.

A operação de filiação está no coração do percurso de Janine Altounian: como herdeira de pais destruídos psiquicamente, "adotando uma postura de engendramento dos ascendentes e de si que passa pela restituição de uma fala daqueles nos quais ela foi abortada". "Escritor-testemunha", "herdeiro-transcritor", "escriba dos mudos que porta em si", "o herdeiro escritor" "conta a história deles e, assim, relata os acontecimentos do mundo que os fizeram ficar mudos".

\footnotetext{
${ }^{21}$ Citação extraída, como as que se seguem, de L'intraduisible : Deuil, mémoire, transmission, op. cit.
} 
Janine Altounian comenta essa mesma estratégia de enunciação no trabalho de um pesquisador e escritor de língua armênia, Krikor Bélédian, que possibilitou, sob o pretexto de uma tese de doutorado em língua estrangeira, Cinquenta anos de literatura armênia na França (1922-1972)22, a tradução e o comentário de relatos literários escritos por Armênios sobreviventes refugiados na França. Relatos sofridos, escritos em uma língua perdida, desaparecida, apagada - o armênio ocidental falado no seio do império otomano - e que ficaram, até a publicação desse trabalho, sem inscrição e sem existência no campo cultural de seu país de acolhida. O salvamento diferido dessa transmissão sob a proteção de um terceiro constituído pela universidade francesa como testemunha do que não teve testemunha assegura a circulação do patrimônio aniquilado e permite ao "filho transmissor" resgatar esses relatos e terminar assim o trabalho de luto. O caráter paradoxal de tal trabalho de enunciação é sublinhado várias vezes por Janine Altounian; ele passa pelo desvio por uma língua e uma cultura deliberadamente silenciosa ou passiva, no que provocou o desenraizamento traumático dessa comunidade, e esse desvio permanece sendo a única salvação possível, o único modo de inscrição de uma catástrofe da qual os herdeiros se liberam ao se tornarem os portavozes e ao deportá-la na língua do outro. "O Eu só se torna Eu passando pelo Outro. Sem essa passagem, o Eu é ameaçado de morte", escreve Krikor Bélédian.

É nos livros de Janine Altounian que se encontra formulada mais fortemente a função desse terceiro salvador para a sobrevivência psíquica, constituído pela figura do estrangeiro, do qual se adota a língua, a cultura e as instituições a fim de inscrever aí uma história ameaçada de ser dissipada; estrangeiro ao qual são "confiados" os traços desse aniquilamento a fim de reconstituir o patrimônio e tornar-se assim "audível a si mesmo e aos outros".

\section{CONCLUSÃO}

É então nessa atualização, em circunstâncias extremas, da função do terceiro salvador, na figura do estrangeiro, que minha reflexão se concluirá. Nossos três autores orquestram, em sua diversidade, a dinâmica, as dores e as estratégias da mestiçagem. As figuras são as do descentramento, do deslocamento, da colocação em perspectiva. Eles

${ }^{22}$ Krikor Beledian, Cinquante ans de littérature arménienne en France. Du même à l'autre, Paris, CNRS Éditions, 2001. 
fazem do distanciamento, do desvio, da desorientação, os instrumentos da conquista de uma liberdade nova. Nas interseções entre vários mundos, eles tecem os laços entre o Oriente e o Ocidente, o passado sequestrado e o presente, o horror sem nome de um genocídio e o que pode ser transmitido disso. Eles transformam uma identidade de cruzamentos em modo de conhecimento do que escapa à nossa compreensão e à nossa apreensão, transpondo as fronteiras entre as disciplinas, revirando as representações, indiferentes às censuras impostas tradicionalmente pelo fato de pertencer a um grupo ou comunidade. Nesse sentido, eles me parecem construir uma das figuras da modernidade do século vinte e um, a das subjetividades que se constroem na experiência do exílio e do deslocamento.

Assim, graças a eles, nossa reflexão procurou estabelecer uma articulação entre os traumatismos históricos e individuais e a necessidade de passar por um terceiro, representado pela cultura, pela língua e pelas instituições do país escolhido para os estudos ou eleito como terra de adoção. Tal reflexão desvela nos deslocamentos dos estudantes - deslocamentos encorajados pelas políticas atuais que insistem na "mobilidade" - forças subversivas. Alguns lutam contra catástrofes políticas, econômicas, humanas que só podem ser pensadas no distanciamento diferenciador de países que dispõem de uma sociedade estável e de instituições garantidoras da cultura e da alteridade. Outros aproveitam a oportunidade de estudar em outro lugar para tentar elaborar, seja em seu trabalho de pesquisa, seja em encontros inabituais, interrogações inéditas com respeito a seu país, sua cultura de origem, seu desejo. Em todos os casos, essas questões são registradas, recebidas, trabalhadas, defendidas na universidade francesa e contribuem para seu brilho influente.

Não é certo que as implicações subjetivas desses percursos sejam reconhecidas e levadas em conta, nem que todos os esforços sejam feitos para acolher e defender essas energias novas que buscam estender em uma afiliação consentida uma interrogação criativa sobre sua identidade. Hannah Arendt em A tradição escondida sublinha a “confusão desesperada desses viajantes parecidos com Ulisses, mas que, diferentemente dele, não sabem quem são", opondo-os aos "refugiados que vão de país em país" e que "representam a vanguarda de seus povos se conservam sua identidade"23. Assim, os deslocamentos dessas vanguardas me parecem oferecer uma chance para os indivíduos,

\footnotetext{
${ }^{23}$ Hannah Arendt, La tradition cachée, Paris, Christian Bourgeois, « Bibliothèque 10/18 »1987.
} 
e para os estados que os recebem, de se sentirem enriquecidos com a confrontação com o estrangeiro. As culturas majoritárias do ocidente têm um papel a desempenhar nas rupturas e remanejamentos incessantes das fronteiras, nos reequilíbrios econômicos e políticos. Em um mundo movediço e instável, no qual as zonas de caos se deslocam, essas culturas têm um dever de hospitalidade sobre o qual o linguista Benveniste nos lembra que a ideia original emerge na antiguidade grega e romana como o direito recíproco de fornecer abrigo e proteção uns aos outros.

O país, a língua e a cultura do outro podem servir como ferramentas ou apoios para colocar em perspectiva o país de origem, pensar o que estava inacessível, obliterado, escamoteado, interrogar o que não se sabia conhecer, formular o que não se via dentro dos limites demasiadamente estreitos de um país, de uma comunidade ou de uma família. O desvio pelo outro é fundador para retornar a si; chance oferecida para a abertura de perspectivas insuspeitadas, "passagens que não se imaginavam”, segundo a expressão de Yosuke Morimoto.

\section{REFERÊNCIAS}

Altounian J., «Ouvrez-moi seulement les chemins d'Arménie ». Un génocide aux déserts de l'inconscient, Paris, Les Belles Lettres, coll. «Confluents psychanalytiques », 1990.

Altounian J., La survivance/Traduire le trauma collectif, Paris, Dunod, coll. «Inconscient et culture », 2000.

Altounian J., L'intraduisible. Deuil, mémoire et transmission, Paris, Dunod, coll. «Psychismes », 2005.

Arendt H., La tradition cachée, Paris, Christian Bourgeois, «Bibliothèque 10/18 », 1987.

Beledian K. , Cinquante ans de littérature arménienne en France. Du même à l'autre, Paris, CNRS Éditions, 2001.

Hinsinger D. et Zaréa P., «Pourquoi faut-il aller si loin ? », Communication faite au colloque «Temps et déplacement», octobre 2004, Actes non-publiés.

Jullien F., Conférence d'ouverture », in Étudier,chercher ailleurs : les étudiants étrangers dans l'université française, Paris, Cité-débats, Octobre 2004, p. 29-49. 
Kristeva J., «Écrire en français » in Tu parles!? Le français dans tous ses états, Paris, Flammarion, 2000, p. 63-74.

Kristeva J., Étrangers à nous-mêmes, Folio essais, 1988.

Kristeva J., La haine et le pardon: Pouvoirs et limites de la psychanalyse III, Paris, Fayard, 2005.

Cheng F., Le dialogue; Une passion pour la langue française, Desclée de Brouwer, 2002.

Morimoto Y., «De la servitude volontaire », in Étudier, chercher ailleurs : les étudiants étrangers dans l'université française, Paris, Cité-débats, Octobre 2004, p. 157-162.

Rouquet-Brutin K., "La transmission de la recherche d'une langue à l'autre », in Étudier, chercher ailleurs : les étudiants étrangers dans l'université française, Paris Cité-débats, Octobre 2004, p. 121-132.

Rouquet-Brutin K., «Dépaysement et mise en perspective de la recherche », Communication faite au colloque «Etudier, chercher ailleurs :Temps et déplacement », octobre 2004, Actes non-publiés.

Rouquet-Brutin : «Destins métisses et constructions identitaires : l'appel à l'autre langue, l'autre culture », Exils, migrations, création, Université paris 12-Val de Marne, Editions Indigo, vol 1, 2008.

Rouquet-Brutin K., «la question des frontières ou l'appel à l'autre », in Mana, L'Harmattan, $\mathrm{n}^{\circ}$ 14-15, 2007.

Rouquet-Brutin K., «Penser dans une autre langue », actes du colloque du Bureau D’Aide Psychologique Universitaire-Pascal, décembre 2006.

Rouquet-Brutin K., «Passer une frontière, trouver une langue », actes du colloque «Violence politique, traumatisme, processus d'élaboration et de création » à Louvainla-Neuve, mai 2009, à paraître

RECEBIDO EM: 01 de novembro de 2012

APROVADO EM: 11 de dezembro de 2012 